\title{
A Case of Rhabdomyoma in Infancy
}

\author{
Hakaru Tasaki, M.D., Junichiro Fukushige, M.D., \\ Sunao Honda, M.D., Ikuho JinnaI, M.D., * \\ Tasuo Takeda, M.D.,* and \\ Hideo MAsakI, M.D.*
}

\section{SUMmaRY}

A case of cardiac rhabdomyoma was presented. She was diagnosed as intraatrial tumor by cardiac catheterization and angiocardiography at 7 months of age.

Two months later, she was undergone open heart surgery, which revealed large rhabdomyoma in the left atrium obstructing the mitral valve.

\section{Additional Indexing Words :}

Cardiac tumor Congestive heart failure Mitral stenosis

Pre-exciting syndrome Surgical treatment

D HABDOMYOMA is the most common primary cardiac tumor in infancy, ${ }^{11}$ but the number of cases diagnosed alive was very limited. Recently, the diagnosis can be confirmed by cardiac catheterization and angiography at an early stage. Some papers have reviewed the clinical presentations of this tumors in infancy. ${ }^{2), 3)}$ In these papers, rhabdomyomas may cause obstruction of the aortic ${ }^{2), 4)}$ or pulmonic valve, ${ }^{3)}$ but obstruction of the mitral orifice by a rhabdomyoma is very rare.

The purpose of this report is to describe the clinical data, including that of cardiac catheterization and angiography, of an infant with congestive heart failure due to mitral stenosis with insufficiency caused by a rhabdomyoma of the left atrium.

\section{Case Report}

A 6-month-old girl was referred to our hospital for the further investigation of heart disease. At birth, she weighed $2.87 \mathrm{Kg}$ and appeared normal. She had normally developed and had been active in her new-born period.

At 1 month of age, she was noticed to have failure to thrive and weak to cry.

At 3 months, she consulted a physician and was treated with digitalis after

From the Departments of Pediatrics and Cardiac Surgery,* Faculty of Medicine, University of Kyushu, Fukuoka, Japan.

Reprint request to: Hakaru Tasaki, M.D., Department of Pediatrics, Faculty of Medicine, University of Kyushu, Higashi-ku, Fukuoka-shi 812, Japan.

Received for publication October 4, 1975. 
a clinical diagnosis of congenital heart disease with congestive heart failure had been made. But congestive heart failure persisted and upper respiratory infections frequently developed. Then she was transferred to our hospital. There was nothing in the family history to suggest neurological or cardiovascular disease.

On admission:

Physical examination revealed mild cyanosis on lips and nail-beds. Her weight was $4.89 \mathrm{Kg}$. The heart rate was 90 per minute and respiratory rate 60 per minute. Peripheral pulses were present and equal. The liver was palpated $3 \mathrm{~cm}$ below the right costal margin. On auscultation of the heart, a loud grade 4 regurgitant systolic murmur and grade 2 diastolic murmur were heard at the fourth intercostal space along the left sternal border which radiated to the apex and the second sound was single. The intensity of the murmur did not change on different occasions and positions of auscultation. There was no focal neurological signs and the skin was normal.

The chest X-ray film showed the evidence of cardiac enlargement with a cardio-thoracic ratio of $65 \%$ and there was a distinct protrusion on the left cardiac border (Fig. 1). Pulmonary vascularity was increased. The electrocardiogram showed right axis deviation $\left(+55^{\circ}\right)$ in the frontal plane and right ventricular hypertrophy (Fig. 2). A short P-R interval with delta wave suggested pre-exciting syndrome. Ultrasoundcardiographic examination presented the evidence of left atrial tumor, there being multiple echoes during diastole behind the anterior mitral leaflet (Fig. 3).

Cardiac catheterization was performed (Table I). No shunt was detected, but the right ventricular and pulmonary artery pressures were elevated. Pulmonary wedge pressure curve was not so well traced, but $\mathrm{c}$ and $\mathrm{v}$ waves were high. No

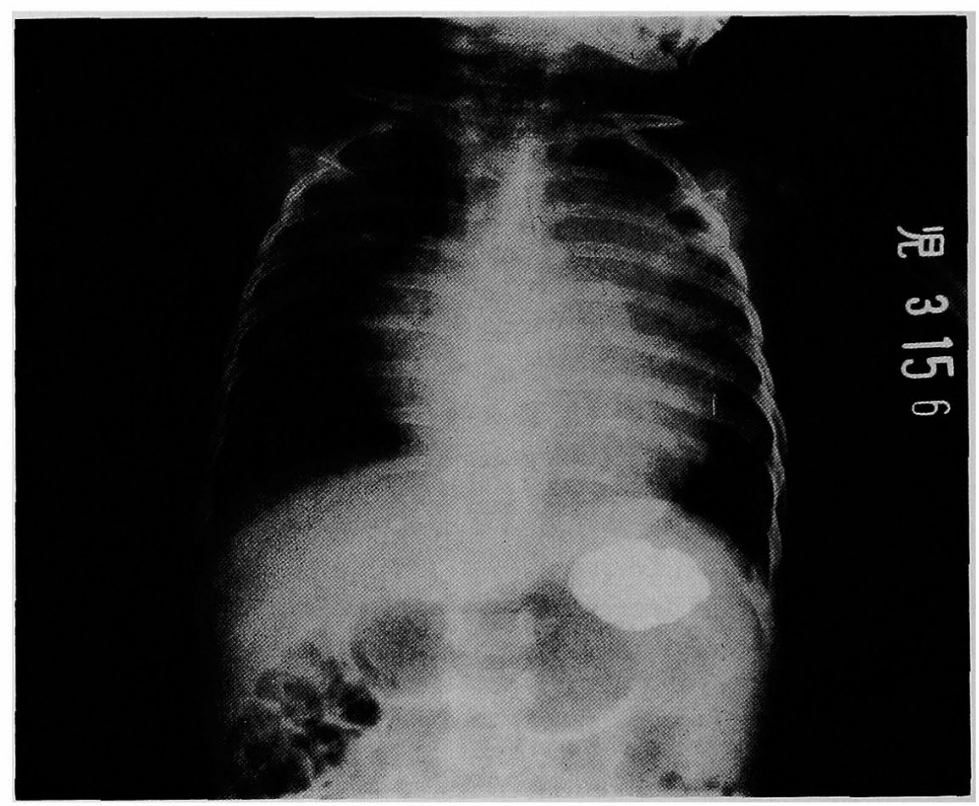

Fig. 1. Chest X-ray film shows cardiomegaly with a hump at the left cardiac border. 

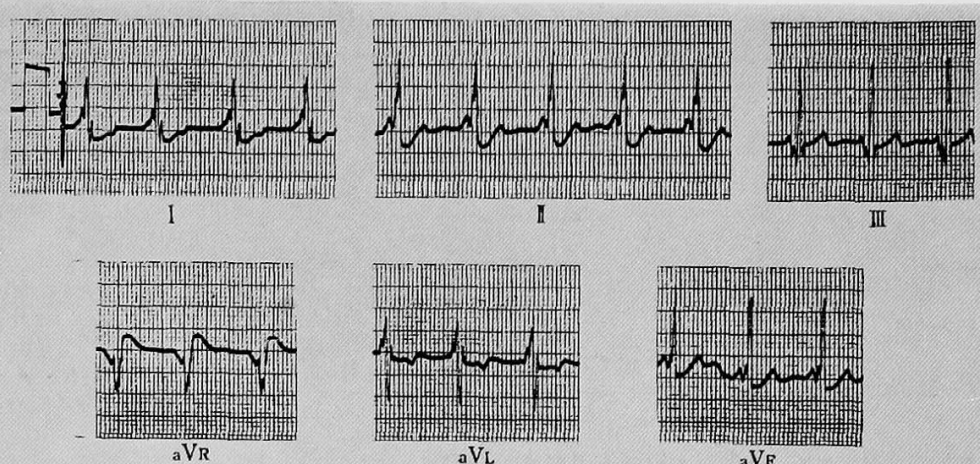

aVF
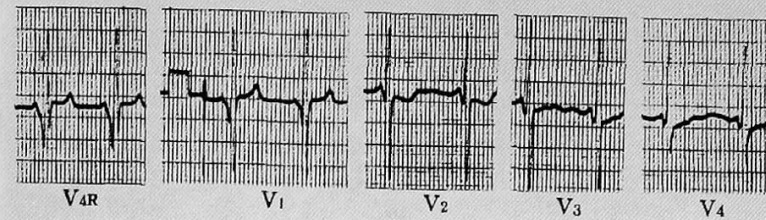

$\mathrm{V}_{3}$

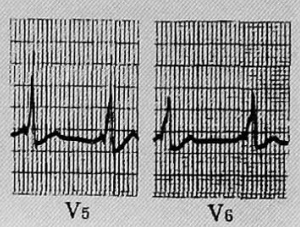

Fig. 2. Electrocardiogram shows short $P-R$ interval. The change of S-T segment suggested digitalis effect.

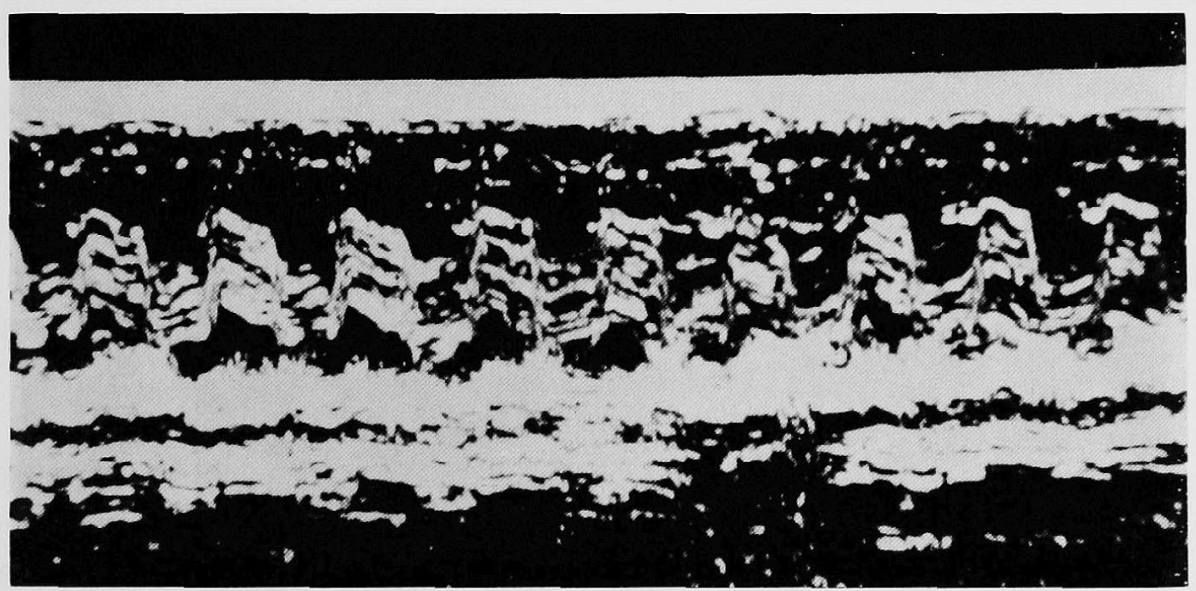

Fig. 3. Echocardiogram. Behind the anterior mitral leaflet, the tumor produces multiple band-like echoes during diastole.

obstructions of the left and right ventricular outflow tract were detected. Pulmonary artery injection of contrast medium with follow-through to the left atrum was performed and left atrial filling defect was noted. Left ventricular angiogram demonstrated moderate mitral regurgitation and again left atrial filling defect (Fig. 4). So left atrial tumor was believed to be present.

At 9-month of age, cardiac surgery was performed because of severe congestive heart failure. A muscle-like tumor was present in the atrial septum. It was protruding into the left atrium and had given rise to mitral stenosis and insufficiency. Total removal of the tumor seemed to be difficult, so it was dissected into 
Table I. Cardiac Catheterization Report

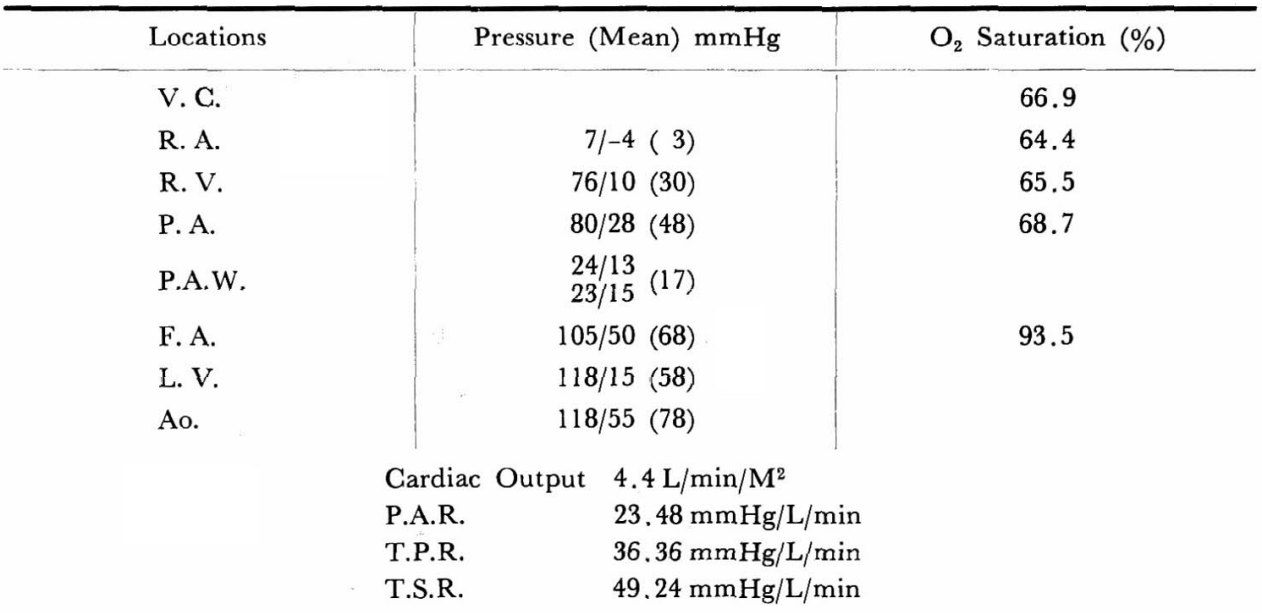

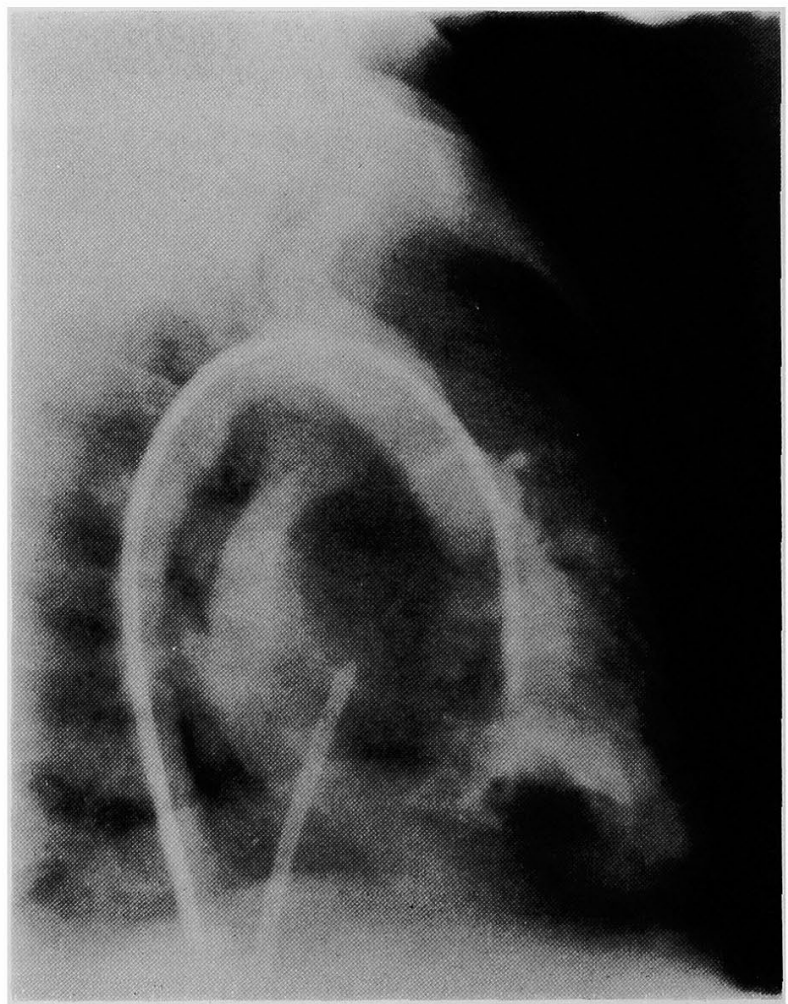

Fig. 4. Selective left ventricular angiogram shows regurgitation of mitral valve and filling defect in the left atrium. 


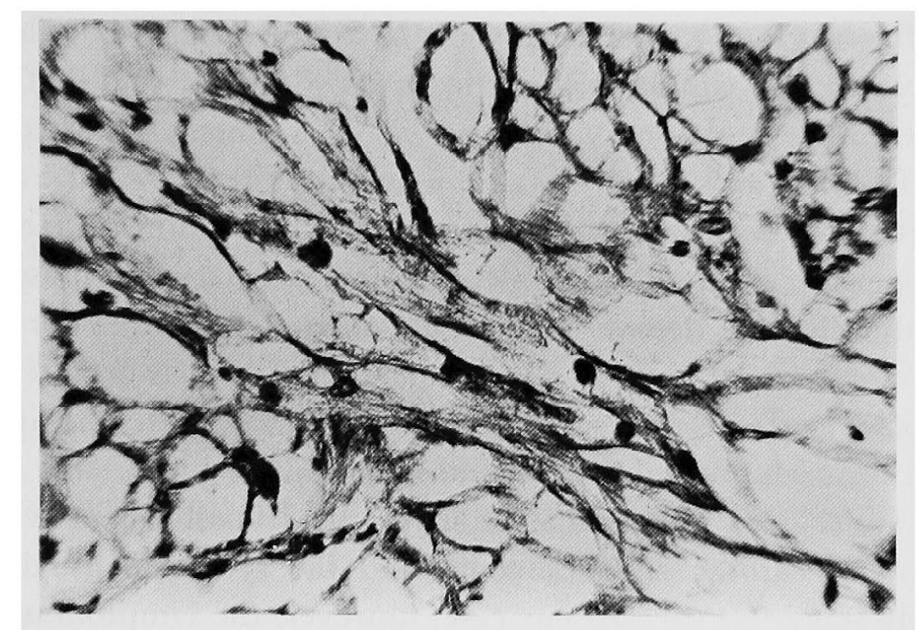

Fig. 5. Microscopic section of the tumor shows rhabdomyoma cells, spider cells and cross striations.

several pieces. Postoperatively, cardiac beats were weak and small. Recovery of beats was unsuccessful and the patient passed away. (Fig. 5).

Microscopically, the cardiac tumor showed large clear rhabdomyoma cells

As the postmortem examination could not be carried out, anomalies of the brain or kidneys were not detected.

\section{Discussion}

Though in many reports were discussed the cardiac rhabdomyoma, ${ }^{2)-9}{ }^{2}$ the true nature remains obscure, while it is usually included in the tumors of the heart. It may form a single mass or multiple nodules and occur mainly in the walls of the ventricles or the ventricular septum. When large, it may project into the cavity of the ventricle. Histological sections present a spongy vacuolated appearance when the tissue has been fixed in aqueous formalin. However, if the tissue is fixed in alcohol, these vacuoles are found to contain a mucopolysaccharide that stains positively by the periodic acid-Schiff reaction, so it is probably glycogen. ${ }^{5)}$

According to Kidder, ${ }^{9)}$ the youngest subject reported on was a 6 -month old fetus and the oldest patient was 45 years old. Forty $\%$ of the patients were dead until 6 months of age, $60 \%$ by the end of 1 year, and $80 \%$ by age of 5 years.

Information on the clinical presentation of cardiac rhabdomyomas in infants are scanty. ${ }^{10}$ ) None the less, these reported cases with sufficient clinical data suggest that a rhabdomyoma of the heart can present itself in various way: obstruction of blood flow, myocardial involvement, and disturbance 
of the cardiac rhythm. Obstruction of the left ventricular outflow tract by a rhabdomyoma may simulate subaortic stenosis ${ }^{2,41,10), 11)}$ and that of the right ventricle resembles pulmonary stenosis. ${ }^{3), 10), 13)}$ Among reported cases, the patient of Golding and Reed ${ }^{12}$ ) was diagnosed as tetralogy of Fallot by the cardiac catheterization data and cine-angiographic findings. He underwent successful open heart surgery and microscopic examination of muscle removed from the infundibulum demonstrated rhabdomyoma. But, to our knowledge, mitral valve obstruction produced by a rhabdomyoma has been reported only once $\left(\right.$ Harich $\left.^{4}\right)$. In that case, a huge tumor projected both into the left atrium and ventricle from the atrial and ventricular septum.

Congestive heart failure due to myocardial involvement is a common complication of cardiac rhabdomyoma and the symptom usually develops in very early stage.4),11),14) In our case, however, the symptom of congestive heart failure has developed relatively late, so we supposed that the failure was not only due to myocardial involvement of rhabdomyoma but also due to mitral failure.

Arrhythmias are commonly observed in intramural tumors. Atrial arrhythmia such as atrial premature contraction, tachycardia, flutter or fibrillation," and ventricular tachycardia ${ }^{10}$ ) have been reported. A short P-R interval with bouts of reciprocal tachycardia was noted in the report of $V$ an der Hauwaert ${ }^{15)}$ and he suggested that the mechanism of it was probably the impulse re-entry by way of accessory atrioventricular pathways in the tumor.

As an autopsy was not permitted, other anomalies could not be detected in our case. According to Shafer, ${ }^{2)}$ if the brain is examined at autopsy, tuberous sclerosis will probably be found in almost all cases.

No surgical treatment has been available till quite recently, but nowadays it is generally said that surgical removal of the tumor should be considered if it is producing significant obstruction of the blood flow. ${ }^{2)}$

\section{ReFERENCES}

1. Gasul BM, Arcilla RA M: Heart Disease in Children. JB Lippincott, Philadelphia, p 1086, 1966

2. Shaher RM, Mintzer J, Farino M, Alley R, Bishop M: Clinical presentation of rhabdomyoma of the heart in infancy and childhood. Am J Cardiol 30: 95, 1972

3. Tsakraklides V, Burke B, Mastri A, Runge W, Roe E, Anderson R: Rhabdomyoma of the heart. Am J Dis Child 128: 639, 1974

4. Harinck E, Moulaert AJMG, Rohwer J, Brom AG: Cardiac rhabdomyoma in infancy. Acta Paediat Scand 63: 283, 1974

5. Heath D: Pathology of cardiac tumors. Am J Cardiol 21: 315, 1968

6. Prichard RW: Tumors of the heart. Arch Pathol 51: 98, 1951

7. Farber S: Congenital rhabdomyoma of the heart. Am J Path 7: 105, 1931 
8. Bigelow $\mathrm{NH}$, Klingen $\mathrm{S}$, Wright AW: Primary tumors of the heart in infancy and early childhood. Cancer 7: 549, 1954

9. Kidder LA: Congenital glycogenic tumors of the heart. Arch Path 49: 55, 1950

10. Van der Hauwaert LG: Cardiac tumors in infancy and childhood. Brit Heart J 33: 125, 1971

11. Kuel KS, Perry LW, Ghandra R, Scott LP: Left ventricular rhabdomyoma. A rare cause of subaortic stenosis in the new born infant. Pediatrics 46:464, 1970

12. Golding $R$, Reed $G$ : Rhabdomyoma of the heart. Two unusual clinical presentation. New Eng J Med 276: 957, 1967

13. Taber RE, Lam GR: Diagnosis and surgical treatment of intracardiac myxoma and rhabdomyoma. J Thorac Cardiovasc Surg 40: 337, 1960

14. Massumi RA, Adkins PC, Reichelderfer TR, Fraga JR, Sampson R: Congenital rhabdomyoma of the heart. J Thorac Cardiovasc Surg 55: 711, 1968

15. Nadas AS, Ellison RG: Cardiac tumors in infancy. Am J Cardiol 21 : 363, 1968 